\title{
APPLICATION OF ANALYTICAL NETWORK PROCESS TO CUSTOMER ORDER SELECTION PROBLEM: A CASE STUDY FOR A STRUCTURAL STEEL COMPANY
}

\author{
Burcu Akyildiz \\ Faculty of Management \\ Istanbul Technical University \\ Istanbul, TURKEY \\ E-mail: akyildizb@itu.edu.tr \\ Cigdem Kadaifci \\ Faculty of Management \\ Istanbul Technical University \\ Istanbul, TURKEY \\ E-mail:kadaifci@itu.edu.tr \\ Ilker Topcu \\ Faculty of Management \\ Istanbul Technical University \\ Istanbul, TURKEY \\ E-mail: ilker.topcu@itu.edu.tr
}

\begin{abstract}
Customer order selection is a very critical and crucial issue for the manufacturing companies as far as their limited capacities are concerned. When the current awarded projects start to cover large portions of the company's design and manufacturing capacities, the company confronts with the decision problem of choosing which customer order next to allocate the remaining scarce capacities properly. The most important objective in this decision problem is usually maximizing the profit, because the firms in manufacturing sector are profit based companies. In order to make this decision, the important evaluation criteria are determined for a selected company as follows: the potential profit rate per unit of time, the compatibility of potential order with the available capacity, the level of potential future order with higher profit, customer credit of future business opportunity, and the negotiability level of production schedule for the order. An Analytical Network Process (ANP)-based decision model is developed by using these criteria to choose the most profitable projects under the limited capacities of the company.
\end{abstract}

Keywords: multi criteria decision making, order selection, structural steel industry. 
ISAHP Article: Akylldiz, Kadaifci, Topcu / Application of ANP to Customer Order Selection Problem: A Case Study for a Structural Steel Company, International Symposium of the Analytic Hierarchy Process 2014, Washington D.C., U.S.A.

\section{Introduction}

Manufacturing companies should made customer order section in the most profitable way while taking care of the constraints of production capacity and man-power capacity. Therefore, having efficient methods for deciding whether to accept or to reject an order to maximize the profit is very important especially when demand exceeds the available capacities and the profitability of the potential orders differs.

In this study, Turkish steel structure industry is concentrated on. Structural steel companies have usually three main divisions: design, manufacturing, and installation. Due to the nature of steel structure industry, the vast majority of the work, described as $90 \%$ by the company under concentration, is completed in the design and factory phases; the installation, remaining $10 \%$, is done with a very little workmanship. Therefore, while the design and manufacturing capacities are stated as capacity constraints for these companies, the need of installation man-power is not stated as one. These companies should select among a set of consumer orders which can be regarded as alternatives that they evaluate on the basis of several, usually conflicting, and incommensurable criteria which may have different priorities. Therefore, the treatment of the decision problem of selecting consumer orders necessitates a multi criteria decision making (MCDM) approach. For this reason, in this study, an Analytical Network Process (ANP)-based decision model that will allow the company to choose the most profitable projects among the alternatives under its limited capacities are developed.

\section{Literature Review}

Maximizing the profit is a mandatory objective for profit-making nature of business. An order with higher profit margin but a longer operation time may not be profitable compared to an order with lower profit margin but a shorter operation time. Hence, instead of total profit, "the potential profit rate per unit of time" can be defined as an evaluation criterion for the order selection decision.

In production sector, the production alternatives are two types: make-to-stock and maketo-order. Because the inventories of the products are constraint resources for make-tostock producers, the concept and methods for rationing inventories are necessary. Some of these are pointed out in the literature. On the other hand, for make-to-order producers, it is not possible to manufacture till confirmed demand is occurred. The capacities of man-hour and production are the constraints. Rationing problems have been studied for these make-to-order companies. Because of the nature of the construction industry, the company in our discussion is not able to stock the product but manufacture in job shop production basis under the restrictive manufacturing capacity. In addition to manufacturing capacity, the man-hour capacity is also limited for design and installation processes. Therefore, "the compatibility of potential order with the available capacity" is regarded as a criterion for the selection decision.

If there is a continuous long-term potential of high demand, the company can prefer to increase the capacity by investing or purchasing a new plant. However, if it is a shortterm problem, expanding the capacity is not possible because of the time constraint. Therefore, to make a choice between the orders by allocating capacities, a mandatory decision occurs for the short-term problems. For make-to-order companies, accepting the

International Symposium of

the Analytic Hierarchy

Process
Washington, D. C. June 29 - July 2, 2014 
ISAHP Article: Akylldiz, Kadaifci, Topcu / Application of ANP to Customer Order Selection Problem: A Case Study for a Structural Steel Company, International Symposium of the Analytic Hierarchy Process 2014, Washington D.C., U.S.A.

order also may create another problem by affecting the available capacities for the future customers. Thus, in this study the short-term problems of the company are focused on and "the level of potential future order with higher profit" is taken as another criterion.

While accepting or rejecting the demand, customer credit of future business opportunity should also be considered. Customer credit is linked to the customer's financial condition and past history of payment and backlog. If the demand of this customer kind is declined, this decision may force the customer to seek alternative suppliers so the company can lose the future business opportunities. Thus sometimes, although the order of a customer is not profitable when it is compared with its alternatives, company may prefer to accept its order. Hence "customer credit of future business opportunity" is chosen as an additional criterion of the model.

The decisions of order acceptance and its production schedule are usually not made independently by neither the customer nor related managers. Contrarily, these decisions are gathered through negotiations between the counterparts. Therefore "the negotiability level of production schedule for the order" can be considered as another criterion.

\section{Objectives}

The proposed decision model is utilized for the decision problem of a construction company as a case study. The selected company is a design, manufacture, and installation company for structural steel and steel parts. The company's plant is located in Turkey and its annual production capacity is 36.000 tons. All sorts of buildings and structures are among the projects the company has realized in Turkey and abroad.

The company has faced and will face with the orders that exceed the capacities of it. It is difficult to make order acceptance between the potential orders for the company as being a production company of which capacities are is inadequate for the incoming demand. Usually, the business development manager, factory manager, and technical office manager of the company are positioned as "Decision Making Units" in order to evaluate the projects. In such a case, because of the capacity constraint, making the wrong choice may cause less profitability for the company. Being a profit-making company, the company aims to maximize its profit under the framework of the existing production and technical office man power constraints. As a result, the purpose of this study is to present a model for making an order selection decision which makes the profit higher when the expansions of the capacities and outsourcing are out of concern.

\section{Methodology}

The authors of this study acting as decision analysts interact with three managers of the company who are in charge of selecting the most suitable alternative, in other words the potential order. They are business development, factory, and technical office managers. We come up with a goal, namely "choosing the most profitable project under the limited capacities of the firm". The cluster of criteria are revealed from the literature review as aforementioned in Section 2 and are justified by the managers: The potential profit rate per unit of time; The compatibility of potential order with the available capacity; The level of potential future order with higher profit; Customer credit of future business opportunity; and The negotiability level of production schedule for the order.

The company is quoting for many tenders. Therefore, there are a lot of projects in the pool as alternatives. In this case study, the below potential projects that are considered to be able to be awarded by the company when bilateral negotiations, the feedbacks, and the

International Symposium of 
estimations are taken into account are stated as the cluster of alternatives: Water sports center in Cengelkoy, Turkey; Factory in Pakistan; Shopping Center in Sapanca, Turkey; Compressor Station in Eskisehir, Turkey; Administrative Building in Gemlik, Turkey; Housing Project in Algeria; and City Hall Project in Lazika, Georgia.

\section{Model Analysis}

After the interviews with the managers, it is understood that goal is affected by criteria and criteria are affected by alternatives as in a typical multi criteria decision problem. Nevertheless, in this decision problem, each criterion also affects alternatives and other criteria as well as alternatives affect each other. As there is an interconnection between the set of criteria and the set of alternatives, feedback relation exists. Fig. 1 exhibits the decision model.

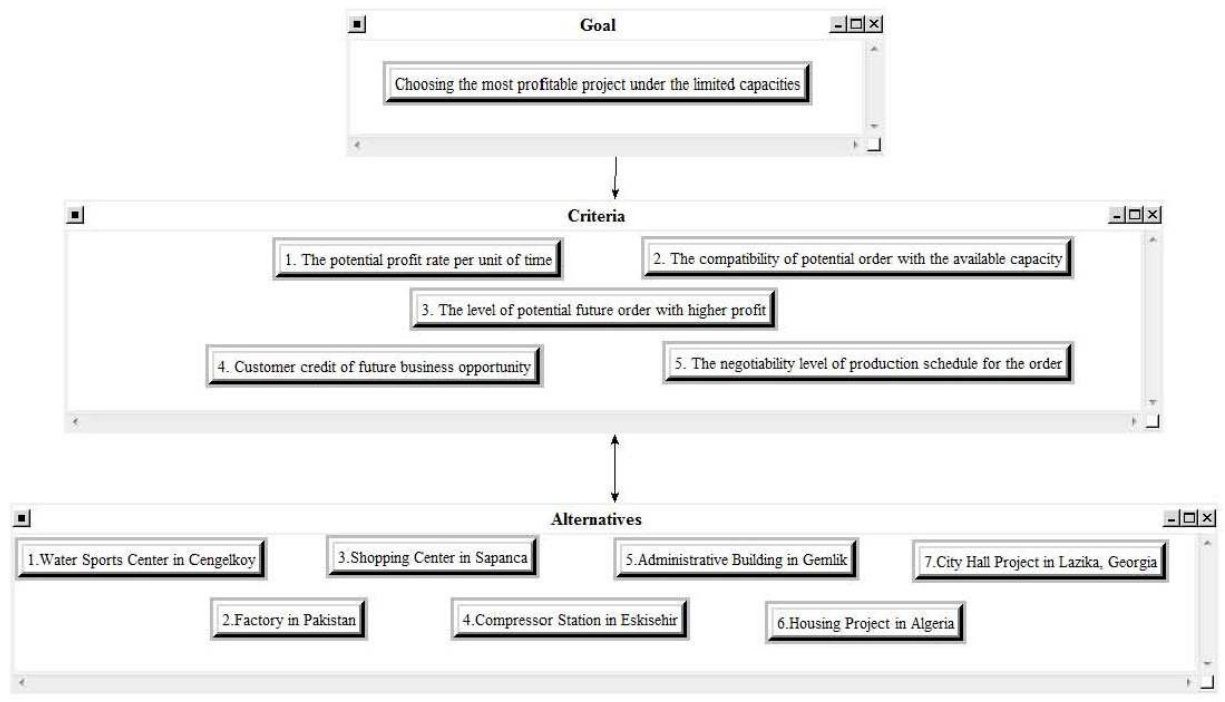

FIGURE I THE DECISION MODEL

Analytical Network Process (ANP) proposed by Saaty is a multi-criteria decision making method that allows decision makers to deal with the dependencies and feedbacks among the constituent parts of a complex structure such as the problem on hand. Therefore in this study, ANP methodology is utilized to treat the problem.

In accordance with ANP steps, the decision analysts request the managers to compare the criteria pairs according to their influence on the goal, on each other criterion, or on each alternative they affect. Similarly, decision makers compare the alternative pairs according to their influence on each criterion or on each other alternatives they affect. In other words, the authors pose pairwise comparison questions to the decision makers for eliciting their judgments with a question using a nine point scale for possible answers: "of the elements in the pair, which one influences the affected element more and how much more?". A pairwise comparison questionnaire survey is conducted in order to assess the judgments of the managers for all possible pairs of elements. The decision analysts compute the geometric means of all paired comparison judgments for each question to reveal the aggregated group judgments. Group judgments are, then, arranged in pairwise comparison matrices which will be input for Super Decisions software.

Finally, the aggregated judgments are synthesized to compute the relative priorities of the criteria and the alternatives. The relative priority of a criterion can be regarded as the 
ISAHP Article: Akylldz, Kadaifci, Topcu / Application of ANP to Customer Order Selection Problem: A Case Study for a Structural Steel Company, International Symposium of the Analytic Hierarchy Process 2014, Washington D.C., U.S.A.

importance of the related evaluation criteria for the order selection decision problem on hand while the relative priority of an alternative can be regarded as the preference for the potential projects of the company. In order to compute priorities, necessary calculations (computation of eigenvector, formation of a supermatrix, computation of the convergence of the supermatrix called as limit matrix) are done by Super Decisions software.

The output of the limit matrix can be converted to the descending priority orders as can be seen at Table I.

TABLE I THE PRIORITIES

\begin{tabular}{|c|c|c|c|}
\hline Potential Projects & Priority & Evaluation Criteria & Priority \\
\hline Administrative Building & $21.64 \%$ & Cust. credit of future bus. opportunity & $35.48 \%$ \\
\hline Shopping Center & $20.82 \%$ & Potential profit rate per unit of time & $26.77 \%$ \\
\hline Housing Project in Algeria & $15.68 \%$ & The negotiability level of prod. sch. & $14.38 \%$ \\
\hline Factory in Pakistan & $12.68 \%$ & The level of potential future order & $12.11 \%$ \\
\hline Water Sports Center & $11.01 \%$ & with higher profit & \\
\hline $\begin{array}{l}\text { City Hall Project in Georgia } \\
\text { Compressor Station }\end{array}$ & $\begin{array}{c}10.37 \% \\
7.81 \%\end{array}$ & $\begin{array}{l}\text { The compatibility of potential order } \\
\text { with the available capacity }\end{array}$ & $26 \%$ \\
\hline
\end{tabular}

\section{Limitations}

There are several weaknesses of the study. First of all, the respondents of the survey are from only the top-management (business development, factory and technical office managers). The respondents can extend to mid-level managers and general managers to prevent this weakness. Besides, the model can be applied for these levels separately and the solutions can be compared with each other in order to evaluate the similar results as well as the differentiations.

\section{Conclusions}

The strength of the study is the availability of gathering the survey from the topmanagement level of the company. Moreover, the criteria of the model are based on the literature as well as the experiences of the top-managers, which is another strength factor for the study. Being able to get the real potential alternative projects of the company is another strength factor of the study.

The study area can be enlarged in such a way that the projects of several other companies in the same sector with the company can be focused on so that the findings of this extended study can be generalized. The projects can be classified based on the features of the projects, and the classified projects can be the new alternatives for the model. In this way, the companies in the same sector with the company can also be analyzed and their priorities can also be evaluated. The comparison of these models' results can give an idea about the differentiation in criteria of the companies in the way of selecting the alternatives.

\section{Key References}

M. Barut and V. Sridharan, "Revenue management in order-driven production systems," Decision Sciences, vol. 36, no. 2, 2005, pp. 287-316.

Y. F. Hung and T. Y. Lee, "Capacity rationing decision procedures with order profit as a continuous random variable," International Journal of Production Economies, vol. 125, 2010, pp. 125-136. 
ISAHP Article: Akylldiz, Kadaifci, Topcu / Application of ANP to Customer Order Selection Problem: A Case Study for a Structural Steel Company, International Symposium of the Analytic Hierarchy Process 2014, Washington D.C., U.S.A.

V. Sridharan, "Managing capacity in tightly constrained systems," International Journal of Production Economics, vol. 56-57, no. 1, 1998, pp. 601-610. 